\title{
Women crossing borders: the changing identities of professional Chinese migrant women in Australia
}

\author{
Christina Ho, University of Technology, Sydney
}

Women are crossing borders at an unprecedented rate. Moreover, especially in Asia, women are increasingly migrating not only as the traditional 'trailing spouse', but as skilled professionals in their own right. Australia has been a major destination for skilled Asian women, largely because of the government's push to meet a domestic skills shortage with the migration of skilled professionals. Guided by a marketoriented approach that views migration through the lens of economic efficiency, the government has constructed its ideal migrant as an educated and highly employable professional who will not become a 'drain' on the public purse.

However, while skilled migrants have been successfully recruited to Australia, there is much evidence that migrants' skills and knowledge are under-utilised and undervalued in the Australian workforce. This is particularly the case for women, who typically experience blocked or downward occupational mobility. These kinds of difficulties faced by migrants in re-establishing their careers have been well documented in Australia and other western countries. Researchers have documented problems with securing recognition of overseas-gained qualifications and work experience, language difficulties, discrimination, and other problems in transferring careers across borders (e.g. Chapman and Iredale 1990; Evans and Kelley 1986; Friedberg 2000; Hawthorne 1997; Iredale 1997).

This paper explores the consequences of this career disruption for migrant women's identities and values. Ironically, although admitted to Australia for their economic 
attributes, migration can ultimately lead skilled women towards a much less marketbased orientation in their lives, as they identify less and less as 'career women' and come to develop other aspects of their identity in their pursuit of 'quality of life' in a new country. This analysis challenges the dominance of economistic research on migrant settlement in Australia and elsewhere, informed by human capital approaches that define migrants in terms of their occupational skills and qualifications (Jupp 2002; Kofman 2000). As Kofman $(2000,56)$ argues, 'The theorisation of skilled migration is not only poorly developed, but is also resolutely economic. It needs to be less compartmentalised and more integrated, recognising the breadth of human experience.' This paper attempts to redress the dearth of research into the social dimension of migration and the perspectives and subjective experiences of migrants themselves.

Ultimately, such an approach also challenges the Australian Government's marketoriented understanding of social citizenship. While the Government sees citizens first and foremost as economic beings that are either productive taxpayers or welfarereceiving 'burdens' on the state, an analysis of the complex, evolving identities of migrant women exposes the conceptual poverty of this economistic framework.

This paper also examines the shifts in identities and values for women migrating to Australia from Hong Kong. In the lead-up to the 1997 handover of Hong Kong sovereignty from Britain to China, educated professionals left Hong Kong in their thousands, mostly bound for the US, Canada and Australia. Although the Chinese Government had agreed to preserve Hong Kong’s legal, economic and social systems for 50 years under the ‘one country, two systems’ formula, many Hong Kong residents feared that the handover would seriously threaten civil liberties and disrupt Hong Kong's economy, education system, and way of life generally (Chan 1990; Cheng and Lo 1995; Mak 1991; Wong 1993).

The Hong Kong Government estimates that the level of emigration increased from an average of approximately 20,000 per year between 1980 and 1986, to around 60,000 in the early 1990s, peaking at 66,000 in 1992 (Skeldon 1995). Thus, in the 1980s and early 1990s, Hong Kong was one of the largest sources of skilled migrants to Australia. Women comprised a large proportion of these skilled professionals, having 
been nurtured by Hong Kong’s economic boom and strong culture of female labourforce participation. Hong Kong women therefore represent one of the most highly skilled cohorts of female migrants to Australia. This paper uses Australian Government quantitative data and qualitative data gained from interviews with 27 Hong Kong women in Australia, most of whom migrated with their families, to explore how they experienced settling in a new country.

\section{Targeting the best and the brightest: A market-based migration policy}

Around the Western world, governments have increasingly viewed migration according to economic criteria, and have been increasingly selective in their admissions policies. In this age of globalisation, governments claim, migrants need to be selected on the basis of their ability to contribute economically to the country. Thus by the early 1990s, most traditional migrant destination countries had introduced legislation placing greater emphasis on migrant skills (United Nations 2002, 21).

Australian governments have been strongly committed to this economistic approach since at least the 1980s. Australia was one of the first countries in the western world to introduce a 'points test' for prospective migrants (Reitz 1998), and by 1999, noneconomic factors had been largely eliminated from the points system (Jupp 2002, 150). Moreover, the 'pass mark' for skilled visa categories is regularly lifted by the government to ensure the selection of increasingly higher-skilled migrants (Vanstone 2004). In addition to passing the points test, skill-based immigrants must meet 'basic requirements': they must be under the age of 45, be proficient in English at the vocational level, have post-secondary qualifications recognised by Australian authorities as suitable for their nominated occupation, and meet Australian requirements for (and have recent experience in) an occupation set out on a skilled occupations list (DIMIA 2003). Since the late 1990s, the majority of new arrivals to Australia have been admitted according to these economic criteria.

The Howard government proudly heralds this reorientation towards skilled migration as a significant achievement. During the 2001 Federal election campaign, the LiberalNational Coalition proclaimed, 'Australia’s skilled migration program is properly targeted to meet Australia’s labour market and economic needs...Under the Coalition, 
Australia's most recent migrants are younger, better skilled and more likely to get employment than ever before' (Liberal-National Coalition 2001, 7). Announcing the 2004-05 migration program, the Federal Government asserted that it was delivering 'the largest Skill Stream in Australia’s history' at around 77,000 people (Vanstone 2004).

Figure 1 below shows the gradual shift in emphasis, from the late 1980s, from family to skilled migration.

Figure 1: Migration program outcomes by stream: 1983-84 to 2002-03

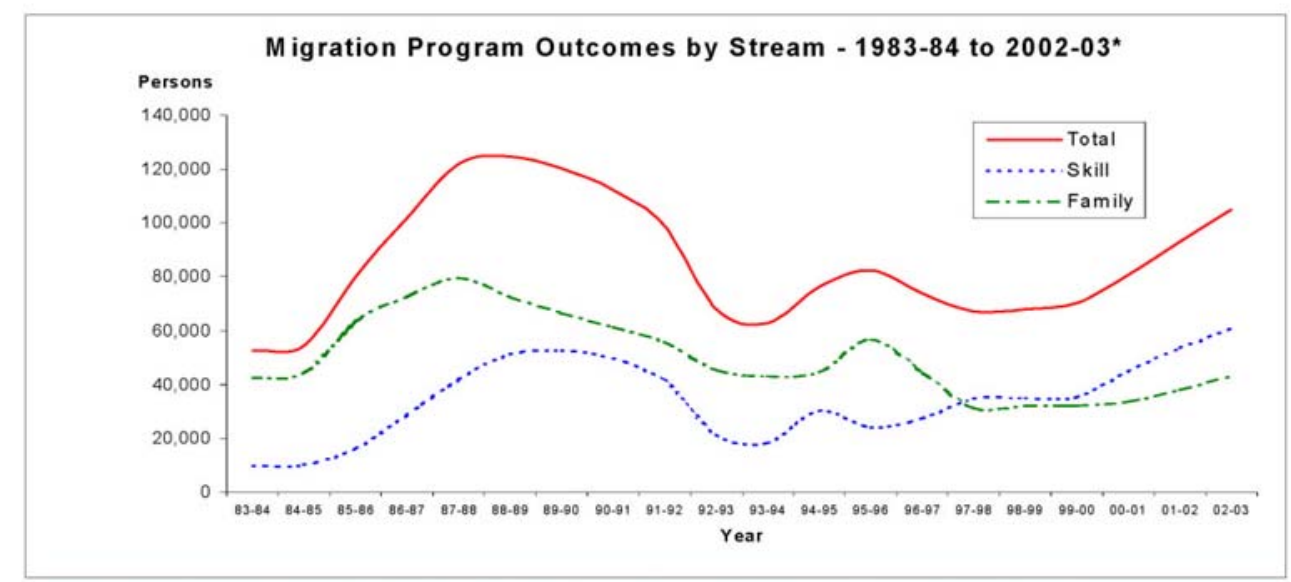

* expected outcome for 2001-02 and planned outcome at mid-point of range for 2002-03

Source: Ruddock 2002: 3

Where do women fit in this picture? As feminist scholars of migration have argued, skilled migration programs are masculinist in their assumptions of what constitutes a 'skill' (Creese and Dowling 2001; Fincher 1997; Kofman 1999). Although migration selection criteria apply equally to men and women, in practice, men are more likely than women to possess the required educational and occupational skills. As Fincher (1995, 212) argues,

Most points are awarded for people who have been employed or trained in those occupations in which men are most likely to be found, both in Australia and overseas, such as managers and administrators, professionals, paraprofessionals and tradespersons. No admission points for skill are awarded for the occupations of clerk, salesperson, plant or machine operator or labourer, the first two of these occupational categories being the ones in which women are heavily concentrated. No points are given for domestic labour.

In addition, men are more likely than women to have the requisite work experience and be able to show a record of career advancement, because they have not taken time 
out of the workforce to raise children (Fincher 1997, 226). Men are also more likely than women to possess better English language skills, another important selection criterion.

Nevertheless, the migration of skilled women is growing, as women gain greater access to higher education and as households come to rely on two incomes (Kofman 2000). The expansion in the movement of professional women also reflects rising demand in feminised labour market sectors, such as nursing and teaching (Raghuram and Kofman 2004). Skilled women are also increasingly migrating as part of skilled households, where both men and women's credentials are assessed by receiving countries (Man 1995; Raghuram and Kofman 2004). Women from Hong Kong typify these trends in many ways, as the next section shows.

\section{Migration and deskilling: Chinese women's experiences of settlement in} Australia

Women migrating from Hong Kong to Australia tend to be highly educated, with a sizeable proportion coming from professional backgrounds, with high levels of qualifications and work experience. According to the 2001 census, Hong Kong-born women were almost twice as likely as all Australian women to hold a higher qualification, as Table 1 shows.

\begin{tabular}{|c|c|c|c|c|}
\hline \multirow[t]{2}{*}{ Qualification } & \multicolumn{2}{|c|}{ Hong Kong-born } & \multicolumn{2}{|c|}{ Total Australian population } \\
\hline & Male & Female & Male & Female \\
\hline Bachelor degree or higher & 30 & 25 & 13 & 13 \\
\hline $\begin{array}{l}\text { Diploma, advanced } \\
\text { diploma or certificate }\end{array}$ & 15 & 15 & 29 & 15 \\
\hline $\begin{array}{l}\text { No post-school } \\
\text { qualifications }\end{array}$ & 55 & 60 & 59 & 71 \\
\hline
\end{tabular}

Hong Kong women are also accustomed to playing an active role in the workforce. This is partly a result of the colony's industrial development, oriented firstly around light manufacturing, and then around services, both of which have been substantial employers of women. Women's labour force participation also reflects a consistently buoyant economy and shortages of labour. Declining birth rates, restrictions on flows 
of mainland Chinese migrants and the 'brain drain' of professionals moving abroad all contributed to labour shortages in the late 1980s and 1990s, creating abundant employment opportunities for local workers. Until the recession of the late-1990s, unemployment rarely exceeded two or three per cent (Man 1997, 196). The shortage of professionals in particular caused many employers to become relatively genderblind. Educated women therefore have been able to enter managerial and administrative positions, enjoying good salaries, attractive fringe benefits and promotions (Man 1997: 194). ${ }^{1}$

Despite this culture of workforce participation, migration to Australia results in a substantial decline in employment levels among Hong Kong women. This is evident in the government-commissioned Longitudinal Survey of Immigrants to Australia (LSIA), which surveyed migrants arriving between 1993 and 1995. Participants were interviewed three times, providing a useful longitudinal portrait of settlement experiences (see DIMIA 2002 for more information about the LSIA). The figures for female primary applicants ${ }^{2}$ from Hong Kong show that while the vast majority (84 per cent) were employed prior to migration, this more than halved (to 39 per cent) after arrival in Australia, and even after three and a half years in Australia, only 55 per cent of women were employed (see Table 2). Meanwhile, the proportion of women engaged in 'home duties' more than tripled after migration, signalling that many women became full-time housewives in Australia.

Table 2: Main activity of female primary applicants from Hong Kong, before and after migration (\%)

\begin{tabular}{lrrr}
\hline Main activity & $\begin{array}{r}12 \text { months prior } \\
\text { to migration }\end{array}$ & $\begin{array}{r}6 \text { months after } \\
\text { migration }\end{array}$ & $\begin{array}{r}3 \frac{1}{2} \text { years after } \\
\text { migration }\end{array}$ \\
\hline Employed & 84 & 39 & 55 \\
Unemployed & - & 6 & 2 \\
Home duties & 10 & 37 & 35 \\
Other & 6 & 18 & 8 \\
Total & 100 & 100 & 100 \\
\hline
\end{tabular}

Source: unpublished LSIA data (Waves 1 and 3)

\footnotetext{
${ }^{1}$ This does not mean that there is no sexism in the Hong Kong labour force. In particular, nonprofessional women such as secretaries and blue-collar workers often confront blatant sexism. For example, recruitment advertisements for secretaries typically specify a preferred age (usually between 20 and 25), and women risk being laid off for requesting maternity leave (Man 1997: 194).
} 
A fall in employment levels was also present among male primary applicants. However, migration to Australia widened the gender gap in employment rates. Prior to migration, men and women had very similar employment rates (84 per cent for women, 85 per cent for men); after three ***and a half years in Australia, the male rate was 79 per cent, almost 25 percentage points higher than the female rate of 55 per cent. $^{3}$

Thus although Hong Kong women are highly educated with strong employment histories, their skills are obviously not being fully utilised in Australia. Despite the fact that their occupational skills helped them gain entry into the country, the act of migration can result in 'de-skilling', as up to half of recent entrants do not engage in paid work.

How are we to understand this process of de-skilling? There is a substantial Australian literature that documents the downward mobility of migrants because of a 'transferability gap' that prevents migrants from continuing their career trajectories in a new country. Researchers have pointed to such factors as the lower return on overseas education (Evans and Kelley 1986; Friedberg 2000; Tram-Nan and Nevile 1988), non-recognition of overseas gained qualifications by the government or employers (Beggs and Chapman 1988; Chapman and Iredale 1990) or the devaluation of migrants’ overseas work experience (Friedberg 2000; Stromback 1984, 1988). They cite various reasons to explain these practices, including preference for the native born, lack of knowledge about overseas education and training systems, prejudice, inadequate processes for formal recognition of overseas-based qualifications, and migrants’ lack of local experience and English proficiency (Hawthorne 1997; Iredale 1997: 100).

Migrant women face additional hurdles re-establishing their careers, notably because of their family responsibilities (Creese and Dowling 2001; Lary et al 1994; Man 1995; Ng 1982). Within migrant families, women's careers are often considered secondary. This means that upon arrival, men’s employment generally assumes priority within

\footnotetext{
${ }^{2}$ Primary applicants are those upon whom the migration application was based.

${ }^{3}$ This gendered effect of migration may be seen as consolidating traditional gender roles within households, a process I have analysed as ‘feminisation' of roles (Ho 2006).
} 
migrant families, while women's primary responsibility is to facilitate the settlement of the family into a new environment. Adjusting to life in a new country typically intensifies women's domestic workload, both in terms of emotional and physical labour.

Concurrently, in migrating, women usually lose sources of domestic support, such as extended family members and hired domestic workers. Researchers on gender and migration have shown that women migrants tend to bear the brunt of the loss of social and domestic networks engendered by migration (Eastmond 1993; Kay 1988; Man 1995, 1997; Meintel et al 1987; Rowland 1991; Yeoh and Khoo 1998). Consequently, as we have seen in the quantitative data above, migration often results in an escalation in women's roles as wives and mothers, and a reduction in their role as income earners.

This pattern sits uneasily with the Australian Government's economistic assumptions about the migration of skilled professionals. While its market-driven migration policy views prospective migrants only as economic beings, the impact of migration on many women is a redefinition of the self away from an economic framework. While they were active 'career women' before migration, the obstacles to re-establishing careers in Australia can mean that women find themselves moving toward non-workoriented spheres of life. The next section explores this from the perspectives of my respondents.

\section{Re-orienting identities: Chinese women move away from market-oriented identities}

As migrants cross borders, they also cross emotional and behavioral boundaries. Becoming a member of a new society stretches the boundaries of what is possible in several ways...One's life and roles change. With them, identities change as well (Espín 1999: 19).

My respondents, who were aged mostly in their 30s and 40s, and lived in Sydney at the time of interview, in many ways typified the experiences of Hong Kong women in Australia. Most had worked full-time prior to migration, and had been extremely career-oriented, continuing to work when their children were young. As mentioned earlier, this work-orientation among Hong Kong women reflects the abundance of 
employment opportunities for women in the Hong Kong economy. It also reflects the high cost of living in Hong Kong, caused by high property prices and a materialistic culture centred around high levels of consumer spending, whether in the form of expensive apartments, electronic consumer items, eating out, or other staples of the Hong Kong middle-class lifestyle.

Women's ability to work full-time is made possible by domestic support from relatives and hired domestic workers. It is not uncommon for households in Hong Kong to consist of grandparents, parents, and grandchildren, residing together, sharing finances, resources and household labour (Lee 2002). Extended families who do not live under the same roof usually live within close proximity of each other, again enabling the sharing of resources and labour. Man $(1995,313)$ explains the rationale for such arrangements:

This pseudo-extended family arrangement is as much an adherence to the Confucian ideal which stresses one's duty to care for the old, as a pragmatic arrangement in response to the high cost of housing, and the shortage of provision by the state of subsidized homes for the aged. Very often, however, the arrangement could be mutually beneficial for all parties. The grandparent (typically the grandmother) or the unmarried aunt is provided for; in return, they are able to help out in housework and child care.

In addition to receiving domestic help from relatives, Hong Kong women often hire domestic workers for daily housework and childcare. Middle- and upper-class Hong Kong households have hired domestic workers since the 1970s, when the Hong Kong Government allowed foreign nationals, mostly from the Philippines and other Southeast Asian countries, to enter the colony to work as 'helpers' (Constable 1997, 29). In 2003, there were approximately 250,000 foreign domestic helpers in Hong Kong, more than half of whom were Filipinos (Torres 2003). The popularity of hiring domestics is enhanced by their low wages. In 2003, the Hong Kong Government cut the already low HK\$3,670 (US\$470) minimum monthly wage for foreign maids by HK\$400 (Torres 2003). In some cases, Hong Kong women choose to work even when their income is only slightly higher than the cost of hiring a domestic worker (Constable 1997, 21). ${ }^{4}$

\footnotetext{
${ }^{4}$ It is important to note that the hiring of a domestic worker does not generally absolve Hong Kong women of responsibility for household labour. While they may delegate tasks to hired workers, women still need to manage household labour, and are blamed by other family members if the work is not done adequately. A 1990s Hong Kong survey found that 72 per cent of wives, compared with four per cent of husbands, were responsible for household chores, while 14 per cent shared the tasks (Cheung et al 1997, 210). As Man argues (1997, 219), while domestic workers relieve middle-class women from
} 
Migration to Australia significantly alters this lifestyle. The loss of domestic support compounds women's difficulties in re-establishing careers, often resulting in a reorientation away from paid work. After migration, many of my respondents left the workforce to assist their families settle in a new environment. When they returned to work, they often did so part-time, structuring their paid work around their family responsibilities (see Table 3).

Table 3: Employment status of respondents, before and after migration

\begin{tabular}{lrr}
\hline & Before migration & After migration* \\
\hline Employed full-time & 25 & 7 \\
Employed part-time & - & 16 \\
Not employed & 2 & 4 \\
Total & 27 & 27 \\
\hline
\end{tabular}

* at time of interview

In seeking work, most women had difficulties gaining positions that were comparable to those they had left behind. In some cases, they accepted lower positions in their field; others changed their occupation or industry completely. Many women spent lengthy periods unemployed. It was rare for them to simply arrive in Australia and continue along their previous career trajectories. Thus, some kind of career sacrifice was experienced by the majority of my respondents.

On the domestic front, many of the women expressed their initial shock and frustration at having to deal with household labour that was previously done by hired domestic workers. Some had never even really acquired skills in cooking, for example, because their lives were so career-oriented in Hong Kong. Most did not know how to drive because they were accustomed to a comprehensive and reliable public transport system. In Australia, being suddenly responsible for domestic tasks in typically large suburban houses, with the extra challenges of looking after gardens and ferrying their children to school and other activities, was unfamiliar terrain.

daily household labour (thus polarising and dividing women along class and racial dimensions), this arrangement 'does not resolve the problems posed by the separation of paid work and housework, and the relegation of housework to women'. Instead, it 'diverts attention from the struggle for an equitable division of household labour between husbands and wives, the provision of socialized services, and 
Despite this, most of my respondents said that they did not regret coming to Australia, because Australian life, while not providing the same kind of domestic support, nor being necessarily supportive of their careers, did open up new sources of personal identity not connected with employment. While previously their lives had been overwhelmingly work-oriented and materialistic, the Australian lifestyle provided more time with the family, more space for leisure and self-development, and ultimately allowed the women to become more independent, away from the influence of family and friends.

For example, Wendy, ${ }^{5}$ a former nurse who migrated to Australia with her husband and two children, took two years out of the workforce while her family adjusted to life in a new country. At the time of interview, Wendy was working part-time as a counsellor. While migration meant putting her career on hold, Wendy had no regrets. In fact, she had come to appreciate Australians' less materialistic lifestyle and ability to 'enjoy life more than the Chinese'. Although migrating to Australia had reduced her family's income, she believed that this was more than compensated for by the extra time they had to spend with the children, for example, on family holidays, which she said they never had in Hong Kong. She explained, '[Now] we're more into the Australian style of having holidays a few times a year, you know. But we are still hard working! [laughs]. But we're aware that we have to enjoy life as well.'

Working less and having a less hectic lifestyle also allowed Wendy to pursue her personal interests: 'I can have more time to myself, to do studying and maybe to read bible or whatever. I've got the time- - but in Hong Kong it seems like you never have enough time, I don't know why.' For these reasons, Wendy said she had noticed a change in herself, such that she was now more concerned with quality of life, and more equipped to make decisions and determine her own fate. While she missed being able to rely on her extended family for support and advice, she had found herself gaining 'emotional independence' and developing the skills to become more assertive in meeting new people and re-establishing her social life.

more flexible work arrangements' $(1997,219)$. Thus the employment of domestic workers reinforces the traditional gender division of labour (Lee 2002, 251).

${ }^{5}$ All names are pseudonyms, and details may have been changed to preserve anonymity. 
Nicola, a young teacher, has a similar story. She migrated to Australia to be with her Australian husband, leaving behind a well-paid position in an elite Hong Kong international school. In Australia, her income was reduced to a third of what it was, and at the time of interview, Nicola worked in two part-time teaching jobs in order to look after her young daughter. However, she considered herself 'really lucky' because although re-establishing work and social networks in Australia was challenging, Nicola believed her quality of life had improved immeasurably:

In Hong Kong I was more highly paid, and the conditions were better, but everything's expensive in Hong Kong, and living conditions are better here. Lots of fresh air and sunshine. Hong Kong's so crowded and polluted. But because I was full-time before, so I felt more belonging, I had more support and resources... I felt I'd made a sacrifice at the beginning but now it's on track. I feel I have freedom to enjoy life here. We have a lovely house right next to the zoo. Sitting on our verandah with the kookaburras and the sunshine, it's like being in a café.

Although she still enjoyed teaching, Nicola felt that she had learnt to appreciate other non-work-related spheres of life that had not been as open to her in Hong Kong.

Carolyn, a nurse who migrated with her husband and daughter, also found that Australian life allowed her to explore other aspects of life besides work. A ward manager in Hong Kong, Carolyn worked in two part-time jobs in Australia, one in a nursing home, and the other as a casual nurse in a public hospital. Although migration had certainly limited her career opportunities and reduced her income, Carolyn felt that life in Australia freed her from the need to conform to the materialism and workorientation that was the norm in Hong Kong:

Coming here, life becomes more simple...In Hong Kong, I would just be working very hard. I would be only one of the normal people. I very pity that sort of life... People in Hong Kong are facing different pressures. You just can't see a good view of your whole life. You don't have perspective. It's only about getting more money. It's a different culture, different norms...I'm better off in terms of the mind-your mind belongs to you yourself. You don't have much pressure.

Similarly, Sally, an accountant who had migrated from Hong Kong with her family, felt that living in Australia allowed her to 'be herself', away from the pressure to 'keep up with the Joneses’ in the competitive social world of Hong Kong:

You can more be yourself... You are unlikely to be affected by other people’s influence... there's less peer pressure - what car you drive, what clothes you wear, what job you have, how 
much money you have and that kind of thing. I think there's less comparison, or less competition. So you can really be yourself more.

For all of these women, despite the downward mobility associated with migration (or perhaps because of it, in some cases), Australian life was a source of greater personal space, away from Hong Kong's work culture, and simply away from the expectations and norms of their social and familial circles. Life in Australia gave these women opportunities to pursue personal interests and define their own lifestyles. ${ }^{6}$

\section{Conclusion}

The Australian Government's market-oriented approach to migration sits uneasily with the experiences of Hong Kong women in Australia. While governmental discourses view citizenship in terms of economics, for these highly skilled, educated migrants, settlement and citizenship in a new country often take them away from market-based identities, and although this entails downward mobility, it can also be simultaneously experienced as liberating.

At one level, Hong Kong women’s shift away from a career orientation reflects a labour market failure-although admitted into the country on the basis of their skills, Australian workplaces are not utilising or rewarding these skills in practice. This ‘transferability gap' has been the subject of much academic work. What I have documented in this paper is another, more subjective, outcome. The shift in Hong Kong women's identities is in many ways a reaction against the highly materialistic, competitive world of their former homeland. In Australia, they see opportunities for living differently-lessening the value placed on economic status and careers and opening up spaces to spend time with loved ones, pursue personal interests and a better quality of life.

\footnotetext{
${ }^{6}$ It should be noted, of course, that these opportunities were available because of the economic status of these women's families. Although their household incomes had invariably fallen after migration, they were still financially comfortable, if not well off, usually because their husbands continued to earn reasonable incomes, and sometimes because of accumulated savings. Thus women's deskilling did not threaten households' financial viability, unlike the experience of many migrant groups, including other Chinese migrants (for example, see Ho 2006 for a comparative analysis of the settlement experiences of women from Hong Kong and China). Indeed, in many ways, the changes in values and lifestyles experienced by my respondents could be seen as an alternative mode of middle-class life, centred more around leisure and the home rather than careers and the workplace.
} 
This is not an argument for neglecting the real labour market problems that exist for many skilled migrants to Australia. In many ways, the decisions that Hong Kong-born women make are not free choices, but rather adaptations to limited opportunities. It could also be argued that some of these women's accounts of their lives are simply putting a positive spin on their experiences. More research is needed to investigate these complexities of migrants' subjective experiences of the process of settling in a new country. Ultimately, all of these questions, and the transition in values and identities documented in this paper seriously challenge the conceptual framework of government policy, which still only sees people as economic beings.

\section{Reference list}

Beggs, J. J. and B. Chapman 1988, Immigrant Wage and Unemployment Experience in Australia, Discussion Paper no. 200, Canberra: Centre for Economic Policy Research, Australian National University.

Chan, D. W. 1990, 'Emigration: Stress and Adaptation in the 1990s,' Hong Kong Journal of Mental Health, 19, 2-4.

Chapman, B. J. and R. R. Iredale 1990, Immigrant Qualifications: Recognition and Relative Wage Outcomes, discussion paper no. 240, Centre for Economic Policy Research, Australian National University, Canberra.

Cheng, J. Y. S. and S. S. H. Lo (eds) 1995, From Colony to SAR: Hong Kong's Challenges Ahead, The Chinese University Press, Hong Kong.

Constable, N. 1997, Maid to Order in Hong Kong: Stories of Filipina Workers, Cornell University Press, Ithaca.

Creese, G. and R. Dowling 2001, 'Gendering Immigration: The Experience of Women in Sydney and Vancouver', Working Paper Series, 01-04, Research on Immigration and Integration in the Metropolis, Vancouver.

DIMIA (Department of Immigration and Multicultural and Indigenous Affairs) 2002, The Longitudinal Survey of Immigrants to Australia [Online], available at http://www.immi.gov.au/research/lsia/index.htm [Accessed: 1 March 2002]. 2003, Skilled Occupations List, form 1121i, Commonwealth of Australia, Canberra.

Eastmond, M. 1993, 'Reconstructing Life: Chilean Refugee Women and the Dilemmas of Exile', in Migrant Women: Crossing Boundaries and Changing Identities, G. Buijs (ed), Berg, Oxford, 35-54.

Espin, O. M. 1999, Women Crossing Boundaries: A Psychology of Immigration and Transformations of Sexuality, Routledge, New York.

Evans, M. D. R. and J. Kelley 1986, 'Immigrants’ work: Equality and discrimination in the Australian labour market', Australia and New Zealand Journal of Sociology, 22, July, 187-207.

Fincher, R. 1995, 'Women, Immigration and the State: Issues of Difference and Social Justice', in Women in a Restructuring Australia: Work and Welfare, A. Edwards and S. Magarey (eds), Allen and Unwin, Sydney. 1997, 'Gender, Age, and Ethnicity in Immigration for an Australian Nation', Environment and Planning A, 29(2), 217-236. 
Friedberg, R. M. 2000, 'You Can’t Take It with You? Immigrant Assimilation and the Portability of Human Capital', Journal of Labor Economics, 18(2): 221-251.

Hawthorne, L. 1997, 'The Question of Discrimination: Skilled Migrants' Access to Australian Employment', International Migration, 35(3), 395-417.

Ho, C. 2006, 'Migration as Feminisation? Chinese women's experience of work and family in Australia', Journal of Ethnic and Migration Studies, 32(3).

Iredale, R. R. 1997, Skills Transfer: International Migration and Accreditation Issues. A Comparative study of Australia, Britain, Canada, New Zealand and the United States, University of Wollongong Press, Wollongong.

Jupp, J. 2002, From White Australia to Woomera: The Story of Australian Immigration, Cambridge University Press, Cambridge.

Kay, D. 1988, 'The Politics of Gender in Exile', Sociology, 22(1): 1-21.

Kofman, E. 1999, 'Female "Birds of Passage” a Decade Later: Gender and Immigration in the European Union', International Migration Review, 33(2): 269-298.

2000, 'The Invisibility of Skilled Female Migrants and Gender Relations in Studies of Skilled Migration in Europe', International Journal of Population Geography, 6: 45-59.

Lary, D., C. Inglis and C. Wu 1994, 'Hong Kong: A Case Study of Settlement and Immigration,' in Immigration and Refugee Policy: Australia and Canada Compared, H. Adelman, A. Borowski, M. Burstein and L. Foster (eds), vol 2, Melbourne University Press, Melbourne, 405-44.

Lee, W. K. M. 2002, 'Gender Ideology and the Domestic Division of Labor in Middle-class Chinese Families in Hong Kong', Gender, Place and Culture, 9(3): 245-60.

Liberal-National Coalition 2001, 'The Howard Government, Putting Australia's Interests First, Election 2001: Immigration-Its Role in Our Future' (policy document).

Mak, A. S. 1991, 'From Elites to Strangers: Employment Coping Styles of New Hong Kong Immigrants,' Journal of Employment Counselling, 28(4): 144-56.

Man, G. C. 1995, 'The Experience of Women in Chinese Immigrant Families: An Inquiry into Institutional and Organizational Processes', Asian and Pacific Migration Journal, 4(2-3): 303-326.

1997, 'Women's Work is Never Done: Social Organization of Work and the Experience of Women in Middle-class Hong Kong Chinese Immigrant Families in Canada', Advances in Gender Research, 2: 183-226.

Meintel, D., M. Labelle, G. Turcotte and M. Kempineers 1987, 'The New Double Workday of Immigrant Women Workers in Quebec', Women's Studies, 13(3): 273-293.

Ng, R. 1982, 'Immigrant housewives in Canada: A methodological note', Atlantis, 8, 111-17.

Raghuram, P. and E. Kofman 2004, 'Out of Asia: Skilling, re-skilling and deskilling of female migrants', Women's Studies International Forum, 27, 95-100.

Reitz, J. G. 1998, Warmth of the Welcome: The Social Causes of Economic Success for Immigrants in Different Nations and Cities, Westview Press, Boulder.

Rowland, D. T. 1991, Pioneers Again: Immigrants and Ageing in Australia, Australian Government Publishing Service, Canberra.

Ruddock, P. 2002, 'Minister announces 2002-03 migration (non-humanitarian) program’, media release, 7 May. 
Skeldon, R. 1995, 'Emigration from Hong Kong: 1945-1994: The demographic leadup to 1997', in R. Skeldon (ed.), Emigration from Hong Kong, The Chinese University Press, Hong Kong, 51-77.

Stromback, T. 1984, 'The Earnings of Migrants in Australia', Conference paper no. 46, Bureau of Labour Market Research.

_ 1988, Migrants, Ethnic Groups and the Labour Market, Policy options paper prepared for the Office of Multicultural Affairs, Canberra.

Torres, M. A. 2003, 'GMA bans HK deployment for Pinays', The Manila Times, March 6.

Tran-Nam, B. and J. W. Nevile 1988, 'The Effects of Birthplace on Male Earnings in Australia', Australian Economic Papers, 27(50): 83-101.

United Nations (Department of Economic and Social Affairs, Population Division) 2002, International Migration Report, United Nations, New York.

Wong, S. L. 1993, 'Hong Kong Migration to Australia,' paper presented at the AsiaPacific Migration Affecting Australia conference, 14-17 September, Darwin.

Vanstone, A. 2004, 'Australia’s Skills and Migrants to Increase’, media release, 1 April.

Yeoh, B. and L. Khoo 1998, 'Home, Work and Community: Skilled International Migration and Expatriate Women in Singapore', International Migration, 36(2), 159-84. 